\title{
Primary non-adherence in Portugal: findings and implications
}

\author{
Filipa Alves da $\operatorname{Costa}^{1} \cdot$ Ana Rita Pedro ${ }^{2} \cdot$ Inês Teixeira $^{3} \cdot$ Fátima Bragança $^{2}$. \\ José Aranda da Silva ${ }^{4} \cdot$ José Cabrita $^{5}$
}

Received: 28 October 2013 / Accepted: 20 March 2015

(C) Koninklijke Nederlandse Maatschappij ter bevordering der Pharmacie 2015

\begin{abstract}
Background Portugal is currently facing a serious economic and financial crisis, which is dictating some important changes in the health care sector. Some of these measures may potentially influence patients' access to medication and consequently adherence, which will ultimately impact on health status, especially in chronic patients. Aims This study aimed at providing a snapshot of adherence in patients with chronic conditions in Portugal between March and April 2012. Setting Community pharmacy in Portugal. Method A cross-sectional pilot study was undertaken, where patients were recruited via community pharmacies to a questionnaire study evaluating the number of prescribed and purchased drugs and, when these figures
\end{abstract}

A very short-version of this work was included in the Annual Report 2012 of the Portuguese Observatory of Health Systems.

Electronic supplementary material The online version of this article (doi:10.1007/s11096-015-0108-1) contains supplementary material, which is available to authorized users.

Filipa Alves da Costa

Alvesdacosta.f@gmail.com

1 Instituto Superior de Ciências da Saúde Egas Moniz, Centro de Investigação Interdisciplinar Egas Moniz, Observatório Português dos Sistemas de Saúde, Campus Universitário, Quinta da Granja, Monte da Caparica, 2825-083 Caparica, Portugal

2 Escola Nacional de Saúde Pública, Grupo de Investigação em Políticas e Administração de Saúde, Observatório Português dos Sistemas de Saúde, Av. Padre Cruz, 1600-560 Lisbon, Portugal

3 Centre for Health Evaluation and Research (CEFAR), Contract Research Organization (CRO), Grupo/Group Associação Nacional das Farmácias (ANF), Observatório Português dos Sistemas de Saúde, R. Marechal Saldanha, 1, 1249-069 Lisbon, Portugal were inconsistent, the reasons for this. Main outcome measures Primary and secondary adherence measures. Failing to purchase prescription items was categorized as primary nonadherence. Secondary nonadherence was attributed to purchasing prescription items, but not taking medicines as prescribed. Results Data were collected from 375 patients. Primary nonadherence was identified in $22.8 \%$ of patients. Regardless of the underlying condition, the most commonly reported reason for primary non-adherence was having spare medicines at home ("leftovers"), followed by financial problems. The latter appeared to be related to the class of medicines prescribed. Primary nonadherence was associated with low income $(<475 € /$ month; $p=0.026$ ). Secondary non-adherence, assessed by the 7-MMAS was detected in over $50 \%$ of all patients, where unintentional nonadherence was higher than intentional nonadherence across all disease conditions. Conclusion This study revealed that more than one fifth of chronic medication users report primary nonadherence $(22.8 \%)$

4 Formifarma, Observatório Português dos Sistemas de Saúde, Rua Luiz Marques - Lote 8, Alto dos Gaios, 2765-448 Estoril, Portugal

5 Faculdade de Farmácia, Sub-grupo de Sócio-farmácia, Universidade de Lisboa, Observatório Português dos Sistemas de Saúde, Av. Prof. Gama Pinto, 1649-003 Lisbon, Portugal 
and more than $50 \%$ report secondary nonadherence. Data indicates that the existence of spare medicines and financial constraints occurred were the two most frequent reasons cited for nonadherence $(47,6-64,8$ and $19-45.5 \%$, depending on the major underlying condition, respectively).

Keywords Diabetes $\cdot$ Hyperlipidemia $\cdot$ Hypertension Medication adherence $\cdot$ Portugal

\section{Impacts of findings on practice}

- Community pharmacists should be aware that potentially one in every five patients do not completely fill their prescription

- For every two patients filling their prescription, one reports nonadherent behaviour if questioned about medication for chronic conditions

\section{Introduction}

The Portuguese Health Care System is primarily public, where all citizens are served by a National Health Service (PNHS), mainly financed through taxes. By contributing to the financing of the PNHS, Portuguese citizens earn the right to have their medicines co-paid by the PNHS, and they pay the remainder (out-of-pocket). The level of copayment attributed will depend on their income, where lower income individuals receive a higher reimbursement for their medicines.

\section{Portuguese society}

Portugal has approximately 10.5 million inhabitants. The basic literacy rate declared by the Central Intelligence Agency (CIA) world book is $95.2 \%$; however, only $67 \%$ of the active population has completed basic education (i.e. 9 years) [1]. The average person earns $1028.57 € /$ month ( $14.400 € /$ year) and the minimum legal salary is $475 € /$ month (6.650 €/year) [2]. Life expectancy at birth has improved considerably over the past 25 years, currently reaching nearly 80 years. Perinatal and infant mortality rates have been at one of the lowest points in the EU in recent years. Mortality rates for some of the key causes of death under the age of 65 years, such as circulatory diseases, have decreased since 2000. However, rates of obesity have been rapidly increasing and the overall smoking rate has remained high [3]. The prevalence of diabetes in Portugal has increased from $11.7 \%$ in 2009 to $12.7 \%$ in 2011 [4]. A large study undertaken in adults (18-65 years old) in Portugal during 2007 reported a prevalence of hypertension of $42.6 \%$ [5] and as much as $47 \%$ for hypercolesterolemia [6].

\section{Adherence}

Adherence to therapy is considered an essential part of patient care and a pre-requisite for the achievement of clinical goals, whilst failure to adhere will lead to suboptimal health outcomes and unnecessary increased health care spending [7]. Adherence rates may vary depending on the illness, medication prescribed and even health care settings, but the literature suggests that they are usually higher among patients with acute conditions compared to those with chronic conditions $[8,9]$. In the latter, this figure is approximately $50 \%$ for symptomatic conditions and as low as $30 \%$ for asymptomatic illnesses [10-12]. A recent systematic review has reinforced this notion by demonstrating that the absence of symptoms has a negative impact on adherence [13]. However, these extrapolations have various flaws, as previously highlighted [14]. A clear example of the limitations involved in substantiating these generalizations is a review on adherence to oral hypoglycemic agents that presents a result ranging from 36 to $93 \%$ [15].

Persistence, a specific domain of adherence which refers to whether patients choose to continue a treatment for the prescribed duration, is a problem across multiple chronic conditions. It has been reported that adherence declines from $79 \%$ in the first 3 months to $25 \%$ after 5 years of treatment [16]. In a Cochrane review on interventions to improve adherence to lipid lowering drug regimen, it has been cited that only "one in every four patients continue taking their medicines long term" [16, 17]. Additionally, a relationship between patient awareness of illness and adherence has been suggested when analyzing discontinuation rates in primary prevention, compared to secondary prevention [18]. Others have suggested that even within the same disease condition, the drug class of choice may influence persistence [19], whilst it has also been suggested that the frequency of administrations plays a determinant role in adherence regardless of the underlying chronic condition [20].

In a recent study by Fischer et al. [21], one of the policy implications when looking at primary adherence was the alarmingly high rate of nonadherence found for the three major conditions contributing to the burden of cardiovascular disease, diabetes, hypertension and hyperlipidemia. Primary nonadherence has been defined as the absence of acquisition of a medicine that has been prescribed [21, 22].

A study by Horne et al. evaluated the relationship between adherence and necessity beliefs and concerns where several comparisons were made including drug classes. This study suggests, despite the limitations of such comparisons, that hypertension, diabetes and cholesterol drugs have similar relationships with adherence for both domains assessed [23].

Several factors have been suggested to influence adherence to therapy and various classifications proposed. 
While the WHO defended the use of four categories: patient-related, medication-related, condition-related and health care team/system-related factors [24], others have proposed a simple dichotomy between intentional and unintentional adherence $[25,26]$, where the first refers to an active decision of the patient and the latter refers to a passive process where the patient fails to adhere to instructions by mechanisms or circumstances, where he assumes little control [27]. One meta-analysis on barriers to adherence in hypertension found forgetfulness as the most common barrier, being one example of unintentional nonadherence [28]. Another recent systematic review which included multiple disease conditions suggested that higher adherence is related to increased perception of the necessity of treatment and conversely with fewer concerns about adverse effects, both examples of intentional nonadherence [23].

Another level to these classifications may additionally be proposed, dividing primary and secondary adherence, where the first refers to the acquisition of medicines and the latter to the actual medicine-taking behaviour once the medicines have been purchased [29].

Most published studies focus on secondary adherence but the implementation of electronic prescription has recently made the focus shift to primary adherence [21]. Secondary nonadherence occurs when patients purchase their medication but do not take it as prescribed [21, 22]. Conversely, primary adherence can be estimated by assessing if all medicines prescribed are indeed purchased. In Portugal, this approach is the most feasible option as patient databases are not yet fully integrated, implying one cannot link prescription data with sales data by using a unique patient code. However, it is important to understand the current prescribing regulation. These indicate each prescription may contain a maximum of four packages. Additionally, there is a limit of two packages per prescription item. There are exceptions, which apply for instance to unitary doses, such as insulin, in which case four packages may be prescribed.

\section{Aim of the study}

This study aimed at providing a snapshot of adherence in patients with chronic conditions in Portugal between March and April 2012. The specific objectives were to determine the overall adherence rate for hypertension, diabetes and cholesterol medications; to evaluate differences between primary and secondary nonadherence; to explore, within secondary adherence, the proportion of intentional versus unintentional nonadherence; and, to evaluate the most common reported reasons for nonadherence.

\section{Ethical approval}

Ethical approval was not sought as collected information was not personal (only demographics and pharmacy identification, the latter being optional) and identification of participants involved was not possible (anonymity). Patients were free to decline participation. As such, the principles of ethical research practices were followed, such as confidentiality and anonymity. Additionally, the researchers had no conflict of interests.

\section{Methods}

A cross-sectional study was undertaken in the metropolitan area of Lisbon between March and April 2012. All pharmacies registered with the regulatory agency were invited to participate $(\mathrm{n}=661)$. Pharmacists were instructed to recruit all patients during 1 month that had a prescription for at least one drug for diabetes (oral), hypertension or hyperlipidemia.

Sample was estimated assuming the metropolitan area of Lisbon population to be 2,821,699 inhabitants. Excluding those aged below 15 years old, as they do not often attend pharmacies and are not likely to be on the chronic medication considered of interest, the population was 2,384,335 inhabitants. Assuming the prevalence of the phenomenon to be $50 \%$, a confidence level of $95 \%$ and a sampling error of $5 \%$, the estimated sample size was 384 participants. It was decided that for political reasons the maximum number of pharmacies was to be involved in patient recruitment. Therefore all 661 pharmacies were invited to participate. Additionally, as the study was to be undertaken over a very short period of time (1 month), one could not expect a high participation rate neither a high recruitment rate from each of the participating pharmacies. The pharmacy participation rate was assumed to be $15 \%$ based on previous studies [30, 31], indicating 99 pharmacies would participate. As such, to achieve the estimated sample size each pharmacy would have to recruit 3.78 patients.

Patients agreeing to participate in the study filled in a questionnaire divided into four parts:

1. Assessment of primary adherence by the pharmacist (evaluating if all medicines prescribed had been purchased). When collecting data on medicines purchased, the overall number of packages acquired on that occasion was considered, regardless of whether it was the same active substance or not (this option is explained by the way the prescriptions are filled, as formerly explained, making this the most feasible option); 
2. Assessment of primary adherence reported by the patient, followed by a description of the reasons for not purchasing all medicines prescribed whenever appropriate. The option to include patients reporting primary nonadherence due to having medicines at home is based on the fact that this may be due to several reasons considered of interest.

3. Assessment of secondary adherence (Considering that this scale used cannot be applied to patients taking medicines for the first time (incident users), as it asks questions about their medicines-related behavior in the past, a filter variable was created to exclude incident users; "please answer only if you have been taking these medicines for more than a month"); evaluating intentional and unintentional nonadherence using an adapted version of the 7-MMAS validated for use in the Portuguese language [32].

4. Socio-economic and demographic characterization of the patient (age, gender, employment situation and income)

All data were analyzed using SPSS version 19.0 using univariate analyses for the characterization of the sample and of the main variables researched, and using bivariate analysis to explore relationships between adherence patterns and part 4 of the questionnaire (socio-demographic characterization). To analyze secondary adherence data, individual items' scores were considered (yes $=1$; no $=0$ ) in addition to the overall MMAS score. The latter was calculated by summing up all individual items, where the higher scores indicate lower adherence. The confidence interval considered was $95 \%$.

\section{Results}

Data from 375 patients were obtained from 32 pharmacies (participation rate $=4.8 \%$ ). The mean number of patients recruited per pharmacy was $11.72(\mathrm{SD}=4.191 ;\{1-15\})$. The overall sample comprised $52.1 \%$ female, with an average age of 66.25 years $(\mathrm{SD}=12.854)$.The sample was primarily composed of retired people $(65.7 \%)$ and $35.5 \%$ of the participants earned less than $475 € /$ month (Table 1).

\section{Primary nonadherence}

The sample comprised mostly patients prescribed with antihypertension medicines $(\mathrm{n}=284)$. Among these patients, $45.1 \%$ were also on antihyperlipidemia medicines $(\mathrm{n}=128)$ and $32.0 \%$ were also on oral antidiabetic medicines $(n=91)$. Fifty patients were simultaneously prescribed medicines from all three classes.
Table 1 Demographic characteristics of sample

\begin{tabular}{lll}
\hline Characteristic & Mean (SD) & Min-max \\
\hline Age & $66.25(12.854)$ & $24-93$ \\
Gender (missing $=26)$ & $\mathrm{n}$ & $\%$ \\
Male & 167 & 47.9 \\
Female & 182 & 52.1 \\
Job situation (missing $=34)$ & $\mathrm{n}$ & $\%$ \\
Active & 88 & 25.8 \\
Unemployed & 29 & 8.5 \\
Retired & 224 & 65.7 \\
Income (missing $=37)$ & $\mathrm{n}$ & $\%$ \\
No income & 17 & 5.0 \\
$<475 €$ & 120 & 35.5 \\
Between 475 and $999 €$ & 100 & 29.6 \\
Between 1000 and $1499 €$ & 54 & 16.0 \\
Between 1500 and $1999 €$ & 20 & 5.9 \\
Between 2000 and $2499 €$ & 16 & 4.7 \\
Over 2500 $€$ & 11 & 3.3 \\
\hline
\end{tabular}

A variable was created to classify patients in terms of primary adherence by calculating the consistency between the number of prescribed packages and the number of packages, as reported by the pharmacist. Data showed that, regardless of the underlying condition, around $80 \%$ of the patients in each subsample were classified as primarily adherent, when considering full agreement between the prescribed and the purchased number of packages. The major difference observed was for nonadherers, since hypertension was the condition with the lower proportion of patients not purchasing any medicine (Table 2).

Considering the overall sample, most patients had two packages prescribed $(\mathrm{n}=113 ; 30.7 \%)$, followed by one $(\mathrm{n}=95 ; 25.8 \%)$ or three $(\mathrm{n}=68 ; 18.5 \%)$. Most patients purchased either one $(\mathrm{n}=122 ; 33.2 \%)$ or two $(\mathrm{n}=112$; $30.4 \%$ ) packages of medicine. Only $2.2 \%$ of the sample were nonadherent as they did not purchase any medicine $(n=8)$. On average there was a difference of 0.32 between the number prescribed and purchased $(\mathrm{SD}=0.678$; $\{0-4\})$. Overall, 283 patients $(77.1 \%)$ were classified as primarily adherent as they purchased all the packages prescribed. Therefore, a considerable minority was found to be partially nonadherent $(22.9 \%)$. Among these, the most common feature was to purchase one package less than the number prescribed $(\mathrm{n}=56 ; 15.3 \%)$, followed by 2 packages less $(\mathrm{n}=23 ; 6.3 \%)$, then three $(\mathrm{n}=3 ; 0.8 \%)$ and finally four $(\mathrm{n}=2 ; 0.5 \%)$.

Bivariate analysis was used to identify factors predicting primary adherence (Table 3 ). This table indicates that low income patients were more frequently seen to adopt nonadherent behaviours $(p=0.026)$, when compared with 
Table 2 Estimated Primary non-adherence (difference between the number of prescribed and purchased medicines)

\begin{tabular}{lcccc}
\hline & Diabetes & Hypertension & Hyperlipideamia & Overall \\
\hline Number of patients & $133(35.5 \%)$ & $284(75.7 \%)$ & $182(48.5 \%)$ & $375(100.0 \%)$ \\
Prescribed packages M (SD) $\{$ min-max $\}$ & $1.83(1.377)\{1-12\}$ & $1.77(0.870)\{1-6\}$ & $1.24(0.439)\{1-3\}$ & $2.63(1.587)\{1-12\}$ \\
Purchased packages M (SD) $\{\min -\max \}$ & $1.65(1.468)\{0-12\}$ & $1.57(0.848)\{0-5\}$ & $1.03(0.520)\{0-3\}$ & $2.31(1.551)\{0-12\}$ \\
$\begin{array}{l}\text { Full agreement between prescribed and } \\
\text { purchased n (\%) }\end{array}$ & $112(84.2 \%)$ & $235(82.7 \%)$ & $144(80.0 \%)$ & $283(77.1 \%)$ \\
Nonadherent (did not purchase any) n (\%) & $12(9 \%)$ & $8(2.8 \%)$ & $21(11.5 \%)$ & $8(2.2 \%)$ \\
Partially nonadherent $\mathrm{n}(\%)$ & $21(15.8 \%)$ & $49(17.3 \%)$ & $36(19.8 \%)$ & $(22.9 \%)$ \\
\hline
\end{tabular}

Table 3 Relationship between estimated primary adherence and hypothesized predicting factors

\begin{tabular}{|c|c|c|c|}
\hline \multirow[t]{2}{*}{ Independent variables } & \multicolumn{3}{|c|}{ Dependent variable } \\
\hline & Adherent $\mathrm{n}(\%)$ & Non-adherent n $(\%)$ & $p$ \\
\hline Gender & & & 0.228 \\
\hline Female & $137(50.0)$ & $39(58.2)$ & \\
\hline Male & $137(50.0)$ & $28(41.8)$ & \\
\hline Job situation & & & 0.074 \\
\hline Active citizens & $74(26.1)$ & $14(16.7)$ & \\
\hline Dependent citizens (retired and unemployed) & 209 (73.9) & $70(83.3)$ & \\
\hline Income & & & 0.026 \\
\hline No income or below $475 €$ & $96(36.6)$ & $35(51.5)$ & \\
\hline More than $475 €$ & $166(63.4)$ & $33(48.5)$ & \\
\hline Age & & & 0.124 \\
\hline Young $(<65$ years $)$ & $131(46.8)$ & $26(36.6)$ & \\
\hline Old ( $\geq 65$ years) & $149(53.2)$ & $45(63.4)$ & \\
\hline Duration of therapy with each class & & & 0.012 \\
\hline Taking OAD $>1$ month & & & \\
\hline Yes & $97(98.0)$ & $5(14.7)$ & \\
\hline No & $2(2.0)$ & $29(85.3)$ & \\
\hline Taking AHT $>1$ month & & & 0.301 \\
\hline Yes & $191(95.0)$ & $66(98.5)$ & \\
\hline No & $10(5.0)$ & $1(1.5)$ & \\
\hline Taking $\mathrm{AC}>1$ month & & & 1.000 \\
\hline Yes & $120(93.8)$ & $42(93.3)$ & \\
\hline No & $8(6.2)$ & $3(6.7)$ & \\
\hline
\end{tabular}

$O A D$ oral antidiabetic drugs, $A H T$ antihypertensive drugs, $A C$ antihyperlipidemia drugs those earning more than $475 € /$ month. Similarly, retired and unemployed citizens were also more frequently involved in such behaviours, when compared with active citizens, albeit this association did not reach significance at the 0.05 level $(p=0.074)$.

\section{Reported primary adherence}

When asking if they had purchased all the medicines prescribed, patients' responses indicated that exactly the same number of hypertensive patients $(n=49)$ regarded themselves as nonadherent. Interestingly, there were two patients with diabetes and two patients with hyperlipidemia that did not admit to being primarily nonadherent, despite purchasing fewer medicines than prescribed.

For those patients reporting that they did not purchase all the medicines prescribed, the reason for that option was assessed and varied by therapeutic group (Table 4).

Regardless of the underlying condition, the most commonly reported reason for primary nonadherence was "still having medicines at home", which can happen because there are variation in packaging quantities (where some last 28 days and others last 60 days), it may result from secondary nonadherence, or simply be a reflex of patient 
Table 4 Description of reported reasons for primary nonadherence by therapeutic group

\begin{tabular}{llll}
\hline & Diabetes $\mathrm{n}(\%)$ & Hypertension $\mathrm{n}(\%)$ & Hyperlipidemia $\mathrm{n}(\%)$ \\
\hline Still has medicines at home & $10(47.6)$ & $35(64.8)$ & $16(48.5)$ \\
The prescription has medicines for too long time & $2(9.5)$ & $5(9.3)$ & $2(6.1)$ \\
I think the medicine does not do me well & $3(14.3)$ & $2(3.7)$ & $2(6.1)$ \\
The medicine is not needed & $0(0.0)$ & $1(1.9)$ & $4(12.1)$ \\
I have some financial problems & $4(19.0)$ & $18(33.3)$ & $15(45.5)$ \\
Other reason & $4(19.0)$ & $6(11.1)$ & $2(6.1)$ \\
Total & 21 & 54 & 33
\end{tabular}

dishonesty. The second most commonly reported reason was having financial problems, which was mentioned by $45.5 \%$ of patients on antihyperlipidemia medicines, $35.6 \%$ of patients on antihypertensives and only by $27.8 \%$ of patients on antidiabetic medicines.

\section{Predictors of primary nonadherence}

A statistically significant association was found between adherence to antidiabetic medication and, both patient gender $(p=0.042)$ and income $(p=0.037)$, where nonadherent behaviour significantly more frequent among females and those earning below $475 €$.

In hypertension, the only variable near significance with nonadherence was income ( $p=0.052)$, where nonadherers earned on average less than adherers.

In patients with hyperlipidemia no variables were significantly associated with adherence behaviour, although differential distribution in terms of income was observed.

\section{Secondary adherence}

The 7-MMAS was used to address therapeutic group adherence for patients medicated for more than 1 month. Nearly all the patients fell into this category \{(diabetes: $\mathrm{n}=126$; $94.7 \%$ ) (hypertension: $\mathrm{n}=257$; $95.9 \%$ ) (hyperlipidemia: $\mathrm{n}=162$; $93.6 \%$ ) (Table 5).

Secondary nonadherence was much higher than primary nonadherence, as levels reached $45 \%$, looking at items independently, compared to $20 \%$ for primary nonadherence. Additionally, unintentional nonadherence was consistently higher than intentional nonadherence across all disease conditions. However, some differences are worth mentioning. Among patients with diabetes, two features were commonly found: admitting to be careless about the time of medicine taking and admitting to taking more medicine because they felt worse. Conversely, there were few patients reporting to have stopped because they felt better. On the other hand, among patients on antihyperlipidemia medicines, forgetfulness and finishing the supply of medicine were the two reasons most commonly given.

Considering the overall score obtained on the MMAS, no differences were found between therapeutic groups (Median value $=1.00$ ). However, when considering that responding yes to any item as being sufficient for nonadherence classification, patients on antihyperlipidemia medicines had slightly higher nonadherence rates, reaching $59.5 \%$ of the responding patients (compared to $58.3 \%$ for patients on antidiabetic medicines and to $54.6 \%$ for patients on antihypertensive medicines).

\section{Discussion}

More than a fifth of patients reported primary nonadherence, that is, not purchasing all their prescribed medicines. This proportion increased to $60 \%$ when looking at specific

Table 5 Reported secondary adherence by underlying condition (as suggested by the therapeutic group prescribed)

\begin{tabular}{|c|c|c|c|}
\hline 7-item MMAS & Diabetes n $(\%)$ & Hypertension $\mathrm{n}(\%)$ & Hyperlipidaemia n (\%) \\
\hline Admitting to have forgotten & $44(34.9)$ & $91(35.4)$ & $73(44.8)$ \\
\hline Admitting to be careless about time & $57(45.6)$ & $90(35.6)$ & $60(37.0)$ \\
\hline Admitting to have stopped because felt better & $11(8.8)$ & $37(14.5)$ & $31(19.1)$ \\
\hline Admitting to have stopped because felt worse & $8(6.3)$ & $12(4.7)$ & $9(5.6)$ \\
\hline Admitting to have taken more because felt worse & $10(7.9)$ & $11(4.4)$ & $1(0.6)$ \\
\hline Admitting to have stopped because did not have more medicines & $33(26.4)$ & $74(29.1)$ & $56(34.6)$ \\
\hline Admitting to have stopped for other reason than medical indication & $13(10.4)$ & $27(10.6)$ & $19(11.8)$ \\
\hline
\end{tabular}


Fig. 1 MMAS scores in the three therapeutic groups analyzed $(\%)$

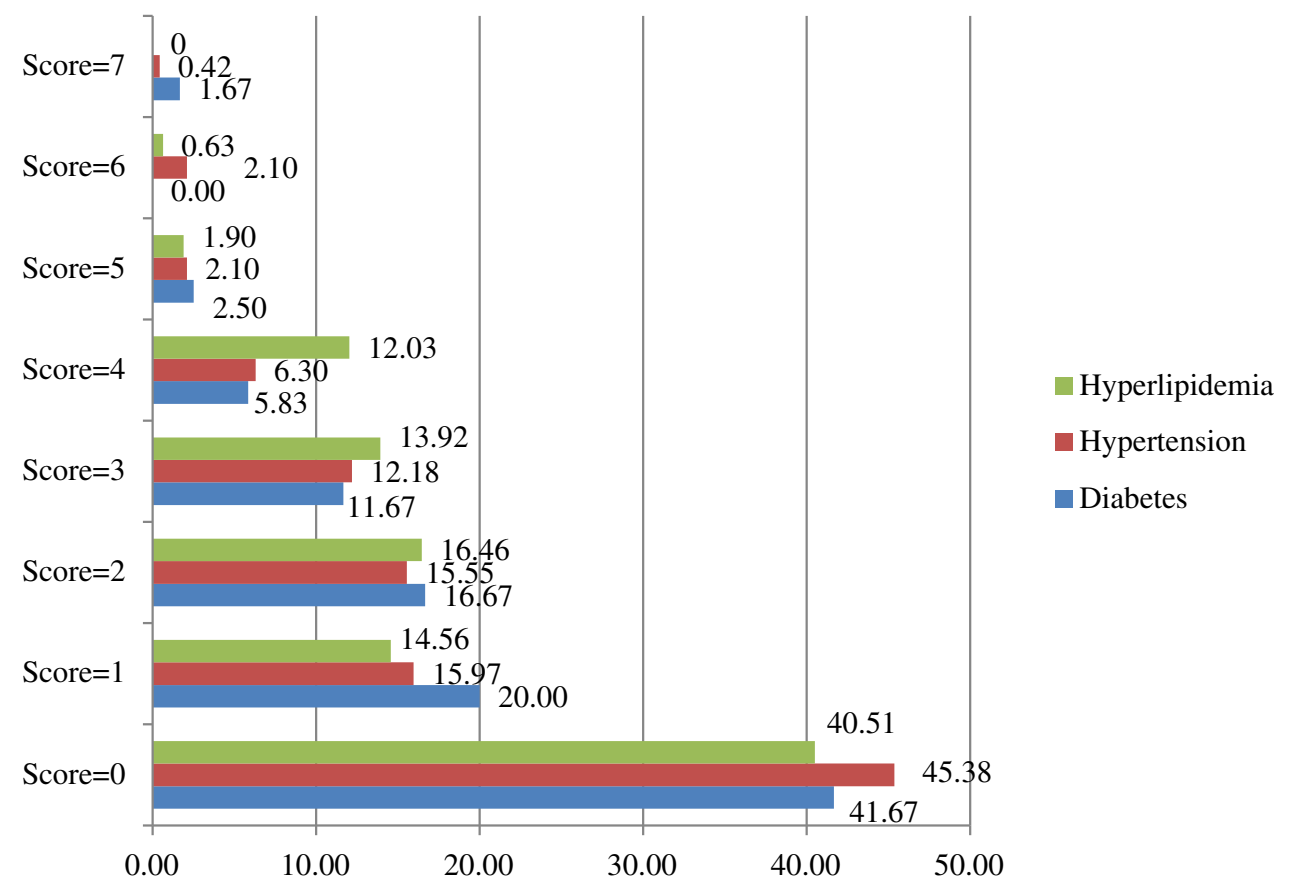

medicines-taking behaviour (Fig. 1), and is consistent with other published data [10]. The most common reason cited for not purchasing all medicines prescribed was having spare medicines at home. This finding is important because it may have serious implications for the safe and effective use of medicines. First, the storage conditions in patients' homes are unknown, and may have consequences for the stability of medicines, as well as the possibility of being used after the expiry date. Secondly, although leftover medicines may result from different sizes of packages, it may also be a consequence of "medicines saving", which is achieved by skipping doses or taking drug holidays. Having leftovers additionally may promote medicine sharing among family members, with potential negative outcomes. Moreover, the prescription may have changed over time, with slight differences in dosage, for example, which will be undetected by patients continually consuming leftover medication. Finally, the introduction of generic medicines, although favoring cost cutting consumers, could possibly play an important role as it may promote therapeutic duplication without patient awareness; when the patient uses leftover medicines, this will be out of the pharmacist's control, who can no longer act to promote the safe and effective use of medicines. An important finding was that, regardless of the underlying condition, the most commonly reported reason for nonadherence was having leftover medicines, a subject with little research where most studies focus on acute treatments [33, 34].

The second most reported reason was having financial constraints. A study undertaken 2 years previously in Portugal indicated that approximately $25 \%$ of patients had failed to purchase their medicines in the preceding year for financial reasons [35].

Similar figures were found in primary partial nonadherence for the analyzed therapeutic groups. The differences detected in nonadherence can be hypothesized to be partly explained by reimbursement to the patient, as antidiabetic medicines have the highest reimbursement $(90 \%$ of the price of medicines is paid by the National Health Service, which is publicly financed) [36]. These findings are supported by previous work indicating a relationship between copayment and primary adherence [37, 38].

Some interesting differences were also found between intentional and unintentional secondary nonadherence, which seem to have plausible explanations. The fact that forgetfulness was more common for hyperlipidemia patients could possibly be explained by the consequences of the condition not being perceived as significant. Additionally, in this class a high proportion reported having stopped because they had run out of medication, consistent with previous literature [39]. Careless behaviour was more often reported by patients with diabetes, which seems logical as this therapeutic class generally requires more daily administrations in comparison with the other therapeutic groups studied. On the other hand, a low proportion of patients with diabetes stopped because they felt better, contrasting with a higher proportion admitting to taking more because they felt worse; these findings seem plausible as type 2 diabetes often has symptomatic episodes that could alert patients to their lack of glycaemic control, in addition to complications arising at later stages of disease progression. 
This study includes data from an important patient sample, albeit not representative of the Portuguese population. In fact, the study was limited to the country's capital. However, although the study was only conducted in an urban area, it may be assumed that these results may not differ significantly from rural areas, as one meta-analysis suggested that the environmental setting had no impact on adherence to cardiovascular and diabetes medication [40]. The participation rate of the pharmacies was very low, albeit in line with other national studies undertaken in recent years, and could be attributed to pharmacists' low motivation to participate in research studies [41]. Indeed, the small sample size was an important limitation of the present study as it had an impact on the possibilities for data analysis and control of confounders. In future, a larger patient sample could be achieved by providing incentives to pharmacists for participation, such as CPD credits. Nonetheless, the sample achieved represented $97.7 \%$ of the estimated.

To overcome the limitation that the pharmacy sample was small, the demographic characteristics of the patients were analyzed. The sample had a majority of female patients, consistent with the work by Martins et al. [42] on pharmacy users. The mean age was slightly higher than expected, but still in line with published data by Costa et al. [43] on patients with chronic conditions visiting pharmacies. Retired people were over-represented, which may be a consequence of responder or selection bias. In future studies, one may consider recording the date and time of patient recruitment to study the occurrence of selection bias.

The method chosen to estimate primary adherence is not exactly the same as the one reported by Fisher et al. [21] and it has not been validated. The definition adopted for this study assumes that not refilling a prescription indicates primary nonadherence, which may not be true. The high proportion of patients reporting having spare medicines at home may indicate nonadherent behaviours but could also have other explanations previously addressed, including a potential social desirability bias. For these reasons, using prescription data at the point of purchase may be considered to add value in comparison to studies looking at pure prescription data, where it is impossible to account for the nonadherers, that is, those deciding not to purchase medication. To overcome this method's limitation, selfreported adherence was also considered and data were internally checked by comparing estimated and reported primary adherence. The overall findings indicate that the results are internally consistent and that patients are truthful about their medicines-taking behaviour. In the near future, it will be possible to verify the accuracy of such explanations as most pharmacies now have the ability to check adherence by refill data registered within their software; however, that is not yet fully implemented.
An additional strength of the study was the simultaneous estimation of secondary adherence. Overall self-reported adherence was lower than could be expected for chronic medication users. However, when exploring various forms of nonadherence, patients admitted to having engaged in such behaviours. Such has been reported by VillaverdeCabral and Silva [35], who found a low proportion of $12 \%$ nonadherence, rising to $30 \%$ or more when detailing different forms of nonadherent behaviour. In the current paper, it has been shown that unintentional nonadherence, in comparison with intentional, confers a higher proportion, another result in line with the aforementioned work [35].

Finally, although it should be acknowledged that perhaps a longitudinal design would be better suited to estimate the true impact of the financial and economic crisis, the approach chosen was appropriate to develop hypotheses in the context of an emerging situation. As such, the study presents useful data to identify the current situation in Portugal in the context of medicines-taking behaviour and the reasons for nonadherence.

\section{Conclusion}

A large minority of patients taking medication for chronic conditions reported primary nonadherence $(22.8 \%)$. The main reason was reported to behaving spare medicines at home. Financial constraints were more frequently cited by patients on a low income $(<475 €)$, who were more commonly found to adopt nonadherent behaviour $(p=0.026)$. Secondary nonadherence was reported by more than $50 \%$ of the sample, mostly arising from unintentional factors. Analysis suggests that the ability to pay for medicines is an important factor in whether patients take their medicine as prescribed and is worth further exploration.

\section{Funding None.}

Conflicts of interest All authors are part of the Portuguese Observatory of Health Systems (OPSS), which is an independent body that annually develops research looking at the impact of political measures taken on the health sector. Research is conducted independently of their academic institutions and is evaluated by peers from other institutions in order to ensure unbiased results are published. For all the above reasons, the authors declare there are no conflicts of interests to be declared. More information about the OPSS can be obtained at http://www.observaport.org/.

\section{References}

1. Portugal. Instituto Nacional de Estatística.Censos 2011: resultados provisórios. Lisboa: Instituto Nacional de Estatística; 2011. p. 1-145. ISBN 978-989-25-0148-2. 
2. OECD. How's life? measuring well-being. Paris: OECD Publishing; 2011. ISBN 9789264201392.

3. WHO. Portugal health system: performance assessment. Copenhagen: WHO Regional Office for Europe; 2010. p. 1-74.

4. Gardete-Correia L, Boavida JM, Fragoso de Almeida JP, Massano Cardoso S, Dores J, Sequeira Duarte J, et al. Diabetes: factos e números 2012: relatório anual do Observatório Nacional da Diabetes. Lisboa: Sociedade Portuguesa de Diabetologia; 2012. p. 1-64. ISBN: 978-989-96663-1-3.

5. Cortez-Dias N, Martins S, Belo A, Fiúza M. Prevalence and patterns of treatment of arterial hypertension in primary health care in Portugal: results of the VALSIM Study. Rev Port Cardiol. 2009;28:499-523.

6. Cortez-Dias N, Martins S, Belo A, Fiúza M. Characterization of lipid profile in primary health care users in Portugal. Rev Port Cardiol. 2013;32(12):987-96.

7. Johnson MJ, Williams M, Marshall ES. Adherent and nonadherent medication-taking in elderly hypertensive patients. Clin Nurs Res. 1999;8:318-35.

8. Jackevicius CA, Mamdami M, Tu JV. Adherence with statin therapy in elderly patients with and without acute coronary syndromes. JAMA. 2002;288:462-7.

9. Cramer J, Rosenheck R, Kirk G, Krol W, Krystal J. VA Naltrexone Study Group. Medication compliance feedback and monitoring in a clinical trial: predictors and outcomes. Value Health. 2003;6:566-73.

10. Haynes RB, McKibbon KA, Kanani R. Systematic review of randomised trials of interventions to assist patients to follow prescriptions for medications. Lancet. 1996;348(9024):383-6.

11. Sherbourne CD, Hays RD, Ordway L, Dimatteo MR, Kravitz RL. Antecedents of adherence to medical recommendations: results from the Medical Outcomes Study. J Behav Med. 1992;15: 447-68.

12. Osterberg L, Blaschke T. Adherence to medication. $\mathrm{N}$ Engl $\mathrm{J}$ Med. 2005;353:487-97.

13. Kardas P, Lewek P, Matyjaszczyk M. Determinants of patient adherence: a review of systematic reviews. Front Farmacol. 2013;4(91):1-16. doi:10.3389/fphar.2013.00091.

14. Mathes T, Pieper D, Antoine S-L, Eikermann M. 50\% adherence of patients suffering chronic conditions-where is the evidence? GMS Ger Med Sci. 2012;10.

15. Cramer JA. A systematic review of adherence with medications for diabetes. Diabetes Care. 2004;27(5):1218-24.

16. Benner JS, Glynn RJ, Mogun H, Neumann PJ, Weinstein MC, Avorn J. Long-term persistence in use of statin therapy in elderly patients. JAMA. 2002;288:455-61.

17. Primatesta P, Poulter NR. Lipid concentrations and the use of lipid lowering drugs: evidence from a national cross sectional survey. BMJ. 2000;321(7272):1322-5.

18. Tsuyuki RT, Bungard TJ. Poor adherence with hypolipidemic drugs: a lost opportunity. Pharmacotherapy. 2001;21(5):576-82.

19. Bramlage $P$, Hasford J. Blood pressure reduction, persistence and costs in the evaluation of antihypertensive drug treatment-a review. Cardiovascu Diabetol. 2009;8:18.

20. Coleman CI, Limone B, Sobieraj DM, Lee S, Roberts MS, Kaur $\mathrm{R}$, Alam T. Dosing frequency and medication adherence in chronic disease. J Manag Care Pharm. 2012;18(7):527-39.

21. Fischer MA, Stedman MR, Lii J, Vodeli C, Shrank WH, Brookhart MA, et al. Primary medication nonadherence: analysis of 195,930 electronic prescriptions. J Gen Intern Med. 2010;25(4):284-90.

22. Solomon MD, Majuumdar SR. Primary nonadherence of medications: lifting the veil on prescription-filling behaviours. J Gen Intern Med. 2010;25:280-1.

23. Horne R, Chapman SCE, Parham R, Freemantle N, Forbes A, Cooper V. Understanding patients' adherence-related beliefs about medicines prescribed for long-term conditions: a meta- analytic review of the necessity-concerns framework. PLoS ONE. 2013;8(12):e80633.

24. Dipollina L, Sabaté E. Adherence to long-term therapies in the elderly. In: Sabaté E, editor. WHO adherence report: a review of the evidence. Geneva: World Health Organisation; 2003. ISBN 92-4-154599-2.

25. Lehane E, McCarthy G. An examination of the intentional and unintentional aspects of medication nonadherence in patients diagnosed with hypertension. J Clin Nurs. 2007;16:698-706.

26. Lowry KP, Dudley TK, Oddone EZ, Bosworth HB. Intentional and unintentional nonadherence to antihypertensive medication. Ann Pharmacother. 2005;39:1198-203.

27. Gadkari AS, McHorney CA. Unintentional nonadherence to chronic prescription medications: how unintentional is it really? BMC Health Serv Res. 2012;12:98.

28. Khatib R, Schwalm J-D, Yusuf S, Haynes RB, McKee M, Khan $\mathrm{M}$, et al. Patient and healthcare provider barriers to hypertension awareness, treatment and follow up: a systematic review and meta-analysis of qualitative and quantitative studies. PLoS ONE. 2014;9(1):e84238.

29. Donovan JL, Blake DR. Patient non-compliance: deviance or reasoned decision-making? Soc Sci Med. 1992;34:507-13.

30. Hughes CM, Hawwa AF, Scullin C, Anderson C, Bernsten CB, Bjornsdottir I, et al. Provision of pharmaceutical care by community pharmacists: a comparison across Europe. Pharm World Sci. 2010;32(4):472-87.

31. Nakash RA, Hutton JL, Jorstad-Stein EC, Gates S, Lamb SE. Maximising response to postal questionnaires-a systematic review of randomised trials in health research. BMC Med Res Methodol. 2006;6(5):111. doi:10.1186/1471-2288-6-5.

32. Delgado AB, Lima ML. Contributo para a Validação Concorrente de uma Medida de Adesão aos Tratamentos. Psicologia, Saúde e Doenças. Sociedade Portuguesa de Psicologia da Saúde. 2001; II(002):81-100.

33. Ramalhinho I, Cordeiro C, Cavao A, Cabrita J. Assessing determinants of self-medication with antibiotics among Portuguese people in the Algarve Region. Int $J$ Clin Pharm. 2014;36(5):1039-47. doi:10.1007/s11096-014-9992-z.

34. Pombo Romero J, Portela Romero M, Vizoso Hermida JR, TasendeSouto M. Evaluation of the pilot program of medicine dispensation in customized doses in Galicia [Spain]. Gac Sanit. 2007;21(1):18-23 (article in Spanish).

35. Villaverde-Cabral M, Silva PA. A adesão à terapêutica em Portugal: atitudes e comportamentos da população portuguesa perante as prescrições médicas. Lisboa: Imprensa de Ciências Sociais. Instituto de Ciências Sociais da Universidade de Lisboa; 2010. ISBN 9789726712572.

36. Portaria no. 924-A/2010. DR. I I Série. 182. (2010-09-17) 4122-(2)-4122-(5).

37. Shah NR, Hirsch AG, Zacker C, Taylor S, Wood GC, Stewart W. Factors associated with first-fill adherence rates for diabetic medications: a cohort study. J Gen Intern Med. 2008;24:233-7.

38. Shah NR, Hirsch AG, Zacker C, et al. Predictors of first-fill adherence for patients with hypertension. Am J Hypertens. 2009;22:392-6.

39. Kiss Z, Nagy L, Reiber I, Paragh G, Molnar MP, Rokszin G, et al. Persistence with statin therapy in Hungary. Arch Med Sci. 2013;9(3):409-17.

40. Murphy GK, McAlister FA, Weir DL, Tjosvold L, Eurich DT. Cardiovascular medication utilization and adherence among adults living in rural and urban areas: a systematic review and meta-analysis. BMC Public Health. 2014;14:544.

41. Aguiar JP, Silva PC, da Costa FA. Análise do perfil de utilização da terapêutica empírica antibiótica instituída em Infeções do Trato Urinário Adquiridas na Comunidade (ITU-AC). Rev Port Farmacoter. 2014;6(1):24-30. 
42. Martins AP, Miranda AD, Mendes Z, Soares MA, Ferreira P, Nogueira A. Self-medication in a Portuguese urban population: a prevalence study. Pharmacoepidemiol Drug Saf. 2002;11: 409-14.
43. Costa FA, Guerreiro JP, Melo MN, Miranda AC, Martins AP, Garção J, et al. Effect of reminder cards on compliance with antihypertensive medication. Int J Pharm Pract. 2005;13:205-11. 